\title{
ERRATUM
}

\section{Erratum zu: Nachrichten - Literatur und Medien}

\section{Redaktion Grundwasser ${ }^{1}$}

Online publiziert: 26. August 2019

(c) Springer-Verlag GmbH Deutschland, ein Teil von Springer Nature 2019

\section{Erratum zu:}

Grundwasser - Zeitschrift der Fachsektion Hydrogeologie 2019

https://doi.org/10.1007/s00767-019-

00422-1

\section{Veröffentlichung der Hydrogeologischen Übersichtskarte von Deutschland 1:250.000 (HÜK250)}

Der Beitrag beschreibt ein Gemeinschaftswerk der Staatlichen Geologischen Dienste der Bundesländer (SGD) und der Bundesanstalt für Geowissenschaften und Rohstoffe (BGR). Leider wurde fälschlicherweise der Versender des Beitrages als Ansprechpartner abgedruckt und nicht die in der eingereichten Notiz benannten SGD \& BGR. Wir bitten dies zu entschuldigen.

Die Online-Version des Originalartikels ist unter https://doi.org/ 10.1007/s00767-019-00422-1 zu finden.

Redaktion Grundwasser geschaeftsstelle@fh-dggv.de

1 Geschäftsstelle der FH-DGGV,

Mühlweg 2, 67434 Neustadt/Wstr., Deutschland 